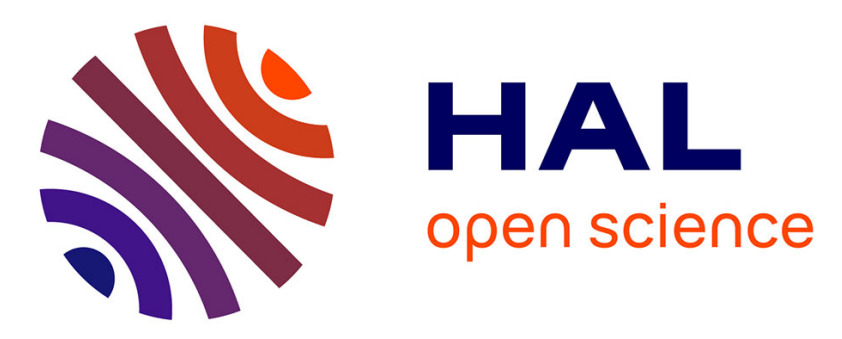

\title{
A multi-event model to study stage-dependent dispersal in radio-collared hares: when hunting promotes costly transience
}

Alexis Avril, Jérôme Letty, Roger Pradel, Yves Léonard, Hugues Santin-Janin, Dominique Pontier

\section{To cite this version:}

Alexis Avril, Jérôme Letty, Roger Pradel, Yves Léonard, Hugues Santin-Janin, et al.. A multi-event model to study stage-dependent dispersal in radio-collared hares: when hunting promotes costly transience. Ecology, 2012, 93 (6), pp.1305 - 1316. 10.1890/11-1742.1 . hal-02126292

\section{HAL Id: hal-02126292 \\ https://hal.science/hal-02126292}

Submitted on 11 May 2019

HAL is a multi-disciplinary open access archive for the deposit and dissemination of scientific research documents, whether they are published or not. The documents may come from teaching and research institutions in France or abroad, or from public or private research centers.
L'archive ouverte pluridisciplinaire HAL, est destinée au dépôt et à la diffusion de documents scientifiques de niveau recherche, publiés ou non, émanant des établissements d'enseignement et de recherche français ou étrangers, des laboratoires publics ou privés. 


\title{
A multi-event model to study stage-dependent dispersal in radio-collared hares: when hunting promotes costly transience
}

\author{
Alexis Avril, ${ }^{1,2,4}$ Jérôme Letty, ${ }^{2}$ Roger Pradel, ${ }^{3}$ Yves Léonard, ${ }^{2}$ Hugues Santin-Janin, ${ }^{2}$ \\ AND Dominique Pontier ${ }^{1}$ \\ ${ }^{1}$ Laboratoire de Biométrie et Biologie Evolutive; CNRS, UMR5558, Université de Lyon, F-69000, Lyon; \\ Université Lyon 1, F-69622, Villeurbanne, France \\ ${ }^{2}$ Office National de la Chasse et de la Faune Sauvage (ONCFS), Direction de la Recherche et du Développement, \\ F-34990, Juvignac; F-45370, Dry; F-44323, Nantes, France \\ ${ }^{3}$ Centre d'Ecologie Fonctionnelle et Evolutive, CNRS, UMR5175, 1919 Route de Mende, F-34293 Montpellier, Cedex 05, France
}

\begin{abstract}
Behavioral ecologists have often assumed that dispersal is costly mainly because of unfamiliarity with traversed habitats during dispersal and energy costs of the movement per se; thus, dispersers that have successfully settled should experience survival rates comparable to those of philopatric individuals. In this paper, we tested that hypothesis using 152 radiocollared European hares in a harvested population. We developed a multi-event capturerecapture model, combining telemetry data and recoveries and separately modeling the foray probability, the settlement probability, and the permanent dispersal probability. The parameterization introduced here raises the possibility of separately testing effects on survival and dispersal probabilities at each stage of dispersal (departure, transience, and settlement). In accordance with our expectations, we reveal that dispersers incur higher mortality risks during transience and the early settlement period than philopatric individuals or settled dispersers. We also found that dispersers suffer from higher risks of being shot. Those results illustrate that unfamiliarity with the habitat during transience makes dispersal costly and that settled dispersers may enjoy survival rates comparable to those of philopatric individuals. Surprisingly, we also found that individuals have a higher probability of foraying during the hunting season. We suggest that hunting and related disturbances increase dispersal costs both by increasing mortality risk during transience and (perhaps) by increasing movement rates. We emphasize the need to take human pressures into account as factors that may drive the demographics of movements in populations.
\end{abstract}

Key words: capture-recapture; dispersal costs; Lepus europaeus; predation risk; telemetry.

\section{INTRODUCTION}

Dispersal, the one-way movement of individuals away from their home ranges (Lidicker 1975), is a key behavioral process in evolutionary ecology and population dynamics with important consequences for gene flow, genetic drift, inbreeding, colonization and the persistence of local populations (Clobert et al. 2001). From a behavioral point of view, dispersal includes three hierarchical stages: emigration from the site of origin, transience, and settlement at a new site (Ims and Hjermann 2001). Ultimately, the realized dispersal results from the combined action of factors on each of the three stages. Environmental influences may promote dispersal at one stage but inhibit it at another; for example, an increasing level of predation may increase emigration but also decrease survival of dispersers (Weisser 2001). Estimates of the realized dispersal/ emigration propensity ratio (i.e., the fraction of emi-

Manuscript received 23 September 2011; revised 6 December 2011; accepted 22 December 2011. Corresponding Editor: F. S. Dobson.

${ }^{4}$ E-mail: alexis.avril@gmail.com grants that successfully immigrate into a new site) and identification of the factors that shape dispersal and its costs are crucial to evaluating most of the theories about the evolution of this trait (Greenwood 1980, Dobson 1982) and understanding its consequences for population dynamics (Hanski 1999). Furthermore, in the context of threatened and managed species, it is particularly important to gain information about the consequences of management for dispersal.

There are important speculations about the survival costs of dispersal. Differences in survival between dispersing and philopatric individuals may occur because sites of departure and arrival differ in quality (Gadgil 1971) and because the transient stage may be costly (Hamilton and May 1977). Movement is energetically expensive and may increase the likelihood of detection by predators (Johnson et al. 2009). Passing through unfamiliar habitats may also increase the likelihood of risky encounters and/or reduce the disperser's ability to find food efficiently (Bowler and Benton 2009) or cover from predators (Larsen and Boutin 1994, Yoder et al. 2004). Hence, provided that the qualities of the old and new habitats do not strongly 
differ, most of the survival differences between philopatric and dispersing individuals are expected to be related to low habitat familiarity and increasing activity rates during transience (Gaines and McClenaghan 1980). When dispersers gain familiarity with the settlement site, such differences should diminish; however, empirical works comparing the fate of dispersers and philopatric individuals have yielded contrasting conclusions (see Bélichon et al. [1996] for a review). These differences may have arisen because some studies (1) compared survival between philopatric individuals and dispersers after settlement, omitting the potential costs related to the transience stage, whereas others (2) combined disperser survival during transience and after settlement or (3) gave biased survival estimates because the fate of emigrants from the study site was uncertain. Although some studies clearly document increasing mortality risks during transience (Yoder et al. 2004), few evaluate dispersal-dependent survival rates or whether survival differences between dispersers and philopatric individuals are related mainly to the transient stage (e.g., Larsen and Boutin 1994).

We explored that hypothesis in the European hare (Lepus europaeus; see Plate 1), a declining game mammal encountered in agricultural lands in Europe. Dispersal in this species occurs predominantly in juveniles, from the end of summer until the end of autumn, overlapping with the harvest (late summer) and the hare-hunting period (autumn; Bray et al. 2007, Avril et al. 2011). Previous work has shown that dispersing hares incurred a higher risk of being shot or killed by predators (mainly red foxes, Vulpes vulpes; Devillard and Bray 2009), but the role of the transient stage in this risk remains unclear. In open landscapes, hares rely primarily on cryptic behavior to limit detection by predators before fleeing and finding refuges (Holley 1993). Hence, we expected dispersers to be more vulnerable during transience as a result of their increasing rates of movement, unfamiliarity with habitats, and vulnerability to hunting.

We undertook a three-year radio-tracking study of 152 hares in a harvested population. From the telemetry data, we derived individual multi-state capture-recapture (MS-CR; Lebreton and Pradel 2002) histories; at each capture, we recorded information about hare survival, causes of mortality, and dispersal stages (i.e., philopatric, transient, or disperser). We analyzed MSCR histories using multi-event models (Pradel 2005), which are an extension of MS-CR models. These models permit estimates of the transition probabilities within and between successive states (alive/dead; philopatric/ disperser) of individuals at each capture, even when the state is not known with certainty. In order to estimate dispersal-dependent survival rates and various effects of factors at each dispersal stage, we developed a new parameterization dealing with the hierarchical decision rules underlying dispersal. To that end, we divided the dispersal probability into three main parameters: (1) The foray probability, modeling the entrance into the transient stage; this parameter, yielding the emigration propensity, is complement of the site fidelity. (2) The settlement probability, modeling the transition from transient to disperser; this parameter is conditional on having forayed and is the complement of returns to the site of origin. And (3) the permanent dispersal probability (conditional on being a disperser), modeling the probability that an individual never returns to its site of origin. In addition, because the detection probability of radio-collared animals mainly depends on a functional collar battery, which in turn may bias estimates of the parameter of interest (Nichols and Hines 1993, Pollock et al. 1995), we also modeled the life expectancy of the radio battery. Using this parameterization, we accurately estimated the movement and survival parameters at each stage of dispersal, as well as various effects of factors such as hunting, which may have non-lethal effects (e.g., disturbances that may be perceived by hares as predation risks).

\section{Methods \\ Species and study site}

We studied a high-density population of hares (about 41 hares $/ \mathrm{km}^{2}$ ) located in an intensive cropping area in the Centre region in central France $\left(47^{\circ} 44^{\prime} 35^{\prime \prime} \mathrm{N}\right.$, $1^{\circ} 21^{\prime} 55^{\prime \prime}$ E). From 2003 to 2005 , both juvenile $(<180$ days old) and adult hares ( $>180$ days old) were trapped at night using unbaited boxes, between April and September each year. Each hare was sexed, weighed, and fitted with an ear tag (Presadom; Chevillot, Albi, France) and radio collar (TW-5 from Biotrack, Wareham, UK, and TXH-2 from Televilt, Lindsberg, Sweden; 50 g, $1500 \mathrm{~m}$ range, 16-month battery life). Age at capture was determined from body mass, skull length, and humerus calcification (details in Bray et al. 2002). Based on body mass and humerus measurements, adults were recognized with high confidence. Among the juveniles, only individuals $<90$ days old were retained because estimates of age were insufficiently precise in older animals and to exclude potential immigrants at the time of capture $(70 \%$ of natal dispersal events were recorded between 90 and 150 days old in our population, Appendix A). At the time of capture, juveniles were 3060 or 60-90 days old. Radiolocations were usually recorded once a week by triangulation and were reported during the day, when most hares rest in their forms. Individuals were always sought using telemetry near their trapping location by default, leading to a high detection probability for stationary individuals. In contrast, dispersers were not always detected soon after departure.

In our population, dispersal occurred mainly in immature individuals and two times more often in males than in females (Avril et al. 2011). In juvenile hares, two main dispersal movements, which differed in the duration of the transient stage and the distances moved, were identified: "one-way" long-distance dis- 
persal, with a short transient stage (about one week), and "shifter" short-distance dispersal, with a transient stage lasting from one week to two months (see Appendix A for more details about birth location, home-range center estimates, and dispersal movements). Natal dispersal distances varied from 704 to 8916 m. In contrast, philopatric juveniles and adults generally remained within $600 \mathrm{~m}$ radius of the site of origin, although some occasional forays $>1000 \mathrm{~m}$ resembled dispersal movements. During the three years of this study, the hare-hunting period continued from the last weekend of September until the end of December, whereas the roe deer (Capreolus capreolus) drive hunt started at the same time and ended in March; although hares are not targeted by roe deer drive hunts, they may nevertheless experience related disturbances.

\section{Multi-state capture-recapture histories}

We summarized the three-year radio-tracking data as capture-recapture histories composed of discrete twoweek long trapping periods separated by two-week intervals (see Appendix A for MS-CR history construction). Each capture history started on 26 March of the year of capture and ended two years later (25 capture occasions in total). We treated the three annual cohorts as though all hares had been born in the same year, to limit the number of capture occasions (the three years yielded 48 capture occasions, which was computationally intractable). We only considered individuals fitted with new radio collars in modeling the life expectancy of the radio battery ( $n=152 ; 78$ juvenile males, 3 adult males, 71 juvenile females). As a proxy for the dispersal state of a hare at each capture occasion, we considered the distance from its location to the site of origin (i.e., an estimate of the unknown birth location for juveniles or the home range center for adults respectively, Appendix A). In the case of multiple telemetry locations during a capture occasion, we used the first one. Because the actual birth location was uncertain, we could have assigned some juveniles to the philopatric state at the time of capture whereas they were actually immigrants that have settled earlier (very few natal dispersal events have been recorded before 60 days old in the European hares (Bray et al. 2007), contrary to the snowshoe hare Lepus americanus (O’Donoghue and Bergman 1992)). In the following analyses, we assumed that such a bias would only lead to an underestimation of the dispersal rates and dispersal stage-dependent survival costs.

We also reported the state of the collar battery, as judged by the quality of the radio signal, for each capture occasion. Finally, we included information about mortality causes that were obtained either by hunter reporting or when discovering the carcass of a radio-collared hare. Hunters were asked to report any killed radio-collared hares and to record the date of death. The location of the kill was not taken into account because it was not recorded precisely. Mortality causes other than hunting were predation (e.g., foxes, raptors), traffic accidents, or "unknown." For individuals dead from causes other than hunting, we could estimate both the location of death (using telemetry) and the date of death (to about one week, as consecutive locations were separated by one week on average).

\section{A multi-event framework}

We analyzed the fates of the studied animals, taking into account the battery life of the radio collar. Since observations at each occasion ("events") did not necessarily match "states," we used multi-event extensions of MS-CR models that dealt with state uncertainty (Pradel 2005). We considered a set $\Omega$ of eight events coded from 0 to 7 and a set $E$ of 16 potential states (described in Appendix A: Table A1), both observable, i.e., at risk of capture (with detection probability $p$ ) or unobservable, i.e., not at risk of capture (null detection probability; Fig. 1).

We considered three observable dispersal states: stationary, transient, and disperser $(\mathrm{S}, \mathrm{T}$, and $\mathrm{D}$, respectively), depending on the individual's telemetry location (i.e., $<1000 \mathrm{~m}$ or $>1000 \mathrm{~m}$ from the birth location) and its previous state. The state $\mathrm{T}$ coded for the transience and the early settlement period. Following Lebreton et al. (1999), we also included three newly dead states (ND) to incorporate recoveries of dead individuals, their locations, and their causes of mortality; we assigned the state $\mathrm{ND}^{\mathrm{H}}$ to individuals recovered shot, $\mathrm{ND}^{\mathrm{S}}$ and $\mathrm{ND}^{\mathrm{TD}}$ to individuals recovered dead due to other causes than hunting, at $<1000 \mathrm{~m}$ or $>1000 \mathrm{~m}$ from the site of origin, respectively. Three final observable states, the nearly lost states (one for each of the preceding dispersal states, i.e., $\mathrm{Nl}^{\mathrm{S}}, \mathrm{Nl}^{\mathrm{T}}, \mathrm{Nl}^{\mathrm{D}}$ ), were used to model the life expectancy of the radio-collar battery. These states were assigned to individuals with a waning radio signal to allow the transition from observable alive states to unobservable alive lost states (L), with a radio collar that was out of order (see Fig.1 and Appendix B). Both newly dead and nearly lost states can occur only once in an individual history.

We considered three alive lost states to describe individuals that were alive with radio collars out of order in each of the three preceding dispersal states (i.e., $\left.\mathrm{L}^{\mathrm{S}}, \mathrm{L}^{\mathrm{T}}, \mathrm{L}^{\mathrm{D}}\right)$. A newly dead lost state $\left(\mathrm{ND}^{\mathrm{L}}\right)$ was also assigned to individuals with non-functioning radio collars that died from causes other than hunting, whatever the dispersal state at the time of death. The two other unobservable states were assigned to individuals in state $\mathrm{T}$ or $\mathrm{D}$ but not at risk of capture: we assigned the states transient temporarily undetectable $\left(\mathrm{T}^{\mathrm{u}}\right)$ and disperser temporarily undetectable $\left(\mathrm{D}^{\mathrm{u}}\right)$ to individuals in state $\mathrm{T}$ or $\mathrm{D}$ that had been not yet relocated and that had a functional radio collar (those states were identified while running the goodness of fit (GOF) tests, which showed that individuals in $\mathrm{S}$ at occasion $t$ that had disappeared at occasion $t+1$ tended to reappear more frequently than expected in $\mathrm{D}$, suggesting that some individuals could not be immedi- 
Departure states (occasion $t$ )
Arrival states Detection Event (occasion $t+1$ ) probability code

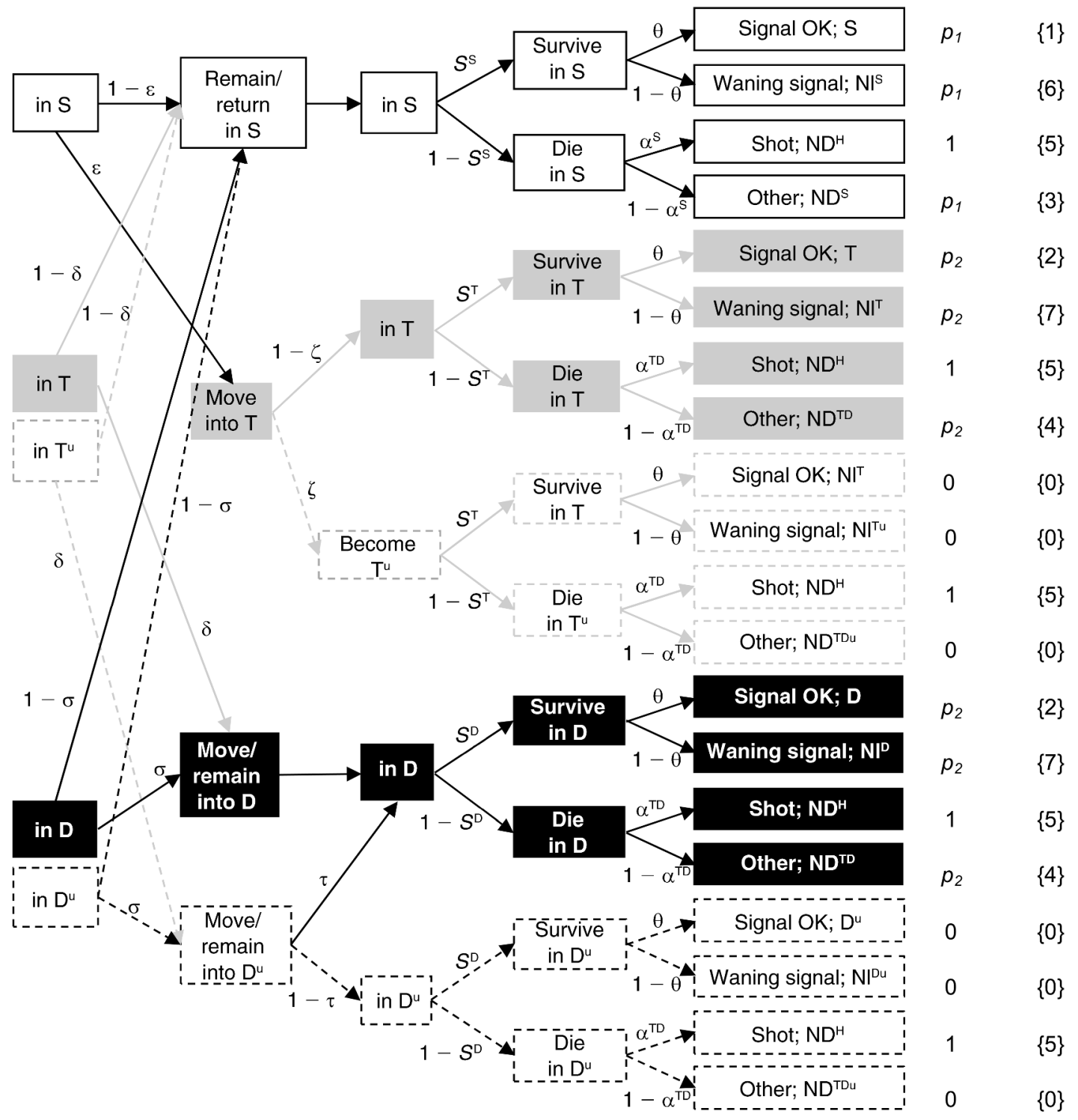

FIG. 1. Fate diagram illustrating state transitions from occasion $t$ to occasion $t+1$ of a radio-collared hare with a functional battery. Stationary hares (state $\mathrm{S}$, white rectangles) can remain in state $\mathrm{S}$ with probability $1-\varepsilon$ or move into the transient state $\mathrm{T}$ (gray rectangles) with probability $\varepsilon(1-\zeta)$ or move into the state transient temporarily undetectable $\left(\mathrm{T}^{\mathrm{u}}\right.$, gray dashed rectangles) with probability $\varepsilon \zeta$. Hares in states $\mathrm{T}$ and $\mathrm{T}^{\mathrm{u}}$ can move into the states disperser $(\mathrm{D})$ or disperser temporarily undetectable $\left(\mathrm{D}^{\mathrm{u}}\right)$ with probability $\delta$ or return back to $S$ with probability $1-\delta$. Hares in state $\mathrm{D}$ and $\mathrm{D}^{\mathrm{u}}$ can return to $\mathrm{S}$ with a probability $1-\sigma$ or remain in $\mathrm{D}\left(\right.$ or $\mathrm{D}^{\mathrm{u}}$ ) with probability $\sigma$. Hares in state $\mathrm{D}^{\mathrm{u}}$ can also become detectable again in (D) with probability $\tau$. Hares in each of the previous states $j$ can survive with probability $S^{j}$ or die with probability $\left(1-S^{j}\right)$ and conditional on having died, they can be shot at distance $j$ with probability $\alpha^{j}$ or died from other causes with probability $1-\alpha^{j}$. Hares that survive can have their radio signal waning with probability $\theta$ at the next occasion or not. Other arrival states are $\mathrm{Nl}^{j}$, nearly lost in state $j$, and $\mathrm{ND}^{j}$, newly dead in state $j$. Detection probabilities of each state are given on the right of the diagram. Numbers in brackets are the event code used in encounter histories. Probability parameters are explained in greater detail in Table 1.

ately relocated after they dispersed; see Appendix C). Finally, the state dead was an absorbing state assigned to individuals that had been dead for more than one capture interval (Lebreton et al. 1999).

We constrained the detection probability to depend on only the distance from the site of origin at which a hare was located (alive or dead). We considered two detection probabilities: $p_{1}$, for individuals detected at $<1000 \mathrm{~m}$ from the site of origin and $p_{2}$, for individuals detected at $>1000 \mathrm{~m}$. As we easily located stationary individuals that had remained within their sites of origin, we expected $p_{1}$ to approach one. For hares recovered 
TABLE 1. List of parameters used in the model, model notations, and their biological interpretation.

\begin{tabular}{|c|c|}
\hline Parameter & Biological significance \\
\hline \multicolumn{2}{|l|}{ Movement } \\
\hline$\varepsilon$ & $\begin{array}{l}\text { Foray probability: probability that an individual in state } \mathrm{S} \text { at occasion } t \text { forays at occasion } t+1 \text {, i.e., passes } \\
\text { into state } \mathrm{T} \text { at occasion } t+1 \text {; complement to the site fidelity. }\end{array}$ \\
\hline$\delta$ & $\begin{array}{l}\text { Settlement probability: probability that an individual in state } \mathrm{T} \text { at occasion } t \text { settles, i.e., passes into the state } \\
\text { disperser } \mathrm{D} \text { at occasion } t+1 \text {; complement to the probability of making short time exploration foray, i.e., } \\
\text { returning into state } \mathrm{S} \text { at occasion } t+1 \text {. }\end{array}$ \\
\hline$\sigma$ & $\begin{array}{l}\text { Permanent dispersal probability: probability that an individual that had settled in state } \mathrm{D} \text { at occasion } t \\
\text { remains in } \mathrm{D} \text { at occasion } t+1 \text {; complement to the probability of making round trip back to the site of } \\
\text { origin, i.e., returning in state } \mathrm{S} \text { at occasion } t+1 \text {. }\end{array}$ \\
\hline \multicolumn{2}{|c|}{ Temporary detectability } \\
\hline$\zeta$ & $\begin{array}{l}\text { Probability of "being temporarily undetectable": probability that an individual in state } \mathrm{T} \text { between occasions } t \\
\text { and } t+1 \text { becomes temporarily undetectable in state } \mathrm{T}^{\mathrm{u}} \text { at occasion } t+1 \text {. }\end{array}$ \\
\hline$\tau$ & $\begin{array}{l}\text { Probability of "retrieving": probability that an individual in state } \mathrm{D}^{\mathrm{u}} \text { at occasion } t \text { becomes detectable again in } \\
\text { state D at occasion } t+1 \text {. }\end{array}$ \\
\hline \multicolumn{2}{|l|}{ Survival } \\
\hline$S^{j}$ & $\begin{array}{l}\text { Probability that an individual alive at the beginning of the occasion } t \text { survives to the beginning of the occasion } \\
t+1 \text { in state } j \text {. }\end{array}$ \\
\hline \multicolumn{2}{|l|}{ Mortality } \\
\hline$\alpha^{j}$ & $\begin{array}{l}\text { Probability that an individual is recovered shot at occasion } t+1 \text { at distance } j \text {, conditional on having not } \\
\text { survived from the beginning of the occasion } t \text { to the beginning of occasion } t+1 \text {. }\end{array}$ \\
\hline \multicolumn{2}{|c|}{ Collar battery } \\
\hline$\theta$ & $\begin{array}{l}\text { Probability that the radio signal wanes from occasion } t \text { to occasion } t+1 \text { conditional on the animal having } \\
\text { survived from the beginning of occasion } t \text { to the beginning of occasion } t+1 \text {. }\end{array}$ \\
\hline \multicolumn{2}{|c|}{ Capture parameter } \\
\hline$p_{j}$ & Detection probability at distance $j$ at occasion $t+1$. \\
\hline \multicolumn{2}{|c|}{ Model examples } \\
\hline$S_{\text {state+age }}$ & Survival varying by state and age in an additive way. \\
\hline$S_{\text {state } \times \text { age }}$ & Survival varying by state and age in interaction. \\
\hline
\end{tabular}

Note: States are $\mathrm{S}$, stationary; $\mathrm{T}$, transient; $\mathrm{T}^{\mathrm{u}}$, transient temporarily undetectable; $\mathrm{D}$, disperser; and $\mathrm{D}^{\mathrm{u}}$, disperser temporarily undetectable.

through hunting, we fixed the detection probability to one because all shot hares should have been reported.

\section{Model and parameter description}

In our model, transitions between occasions $t$ and $t+$ 1 were governed by the product of the state transition matrix $\boldsymbol{\Phi}_{t, t+1}$ and the encounter probability matrix $\mathbf{B}_{t+1}$. We viewed the transition matrix $\boldsymbol{\Phi}_{t, t+1}$ between occasion $t$ and occasion $t+1$ as a five-step process corresponding to the product of the movement-transition matrix $(\mathbf{T})$, the temporary detectability matrix (D), the survival matrix (S), the mortality cause matrix (M), and the collar-battery matrix $(\mathbf{C})$, such that $\boldsymbol{\Phi}_{t, t+1}=\mathbf{T} \times \mathbf{D} \times \mathbf{S} \times$ $\mathbf{M} \times \mathbf{C}$. In this parameterization, we assumed that movement between capture occasions $t$ and $t+1$ occurred at the beginning of the interval between capture occasions, such that survival/mortality causes and detection probabilities depended on the arrival state at occasion $t+1$. Each step involved different parameters given in Table 1. Full details regarding transition matrices and fate diagrams are given in Appendix B. We modeled the probability $\theta$ that the radio signal wanes as a function of the age of the battery using the logit link logit $(\theta)=\beta_{0}+\beta_{1} \times X_{i}$, where $X_{i}$ was a continuous time covariate indicating the number of capture occasions since the initial capture; removing the radio transmitter step did not change the main results presented later (Appendix D: Figs. D2 and D3).

\section{Goodness of fit tests}

GOF tests are not available for multi-event models with a mixture of live recaptures and dead recoveries (Pradel et al. 2003, 2005). Therefore, we resorted to ad hoc procedures to examine lack of fit and variation in the data (see Appendix C). The results led us to identify the states $\mathrm{T}^{\mathrm{u}}$ and $\mathrm{D}^{\mathrm{u}}$, in which detection was impossible. To be conservative during model selection, we used an overdispersion coefficient, $\hat{\mathrm{c}}=1.23$, estimated from the GOF tests.

\section{Model selection}

We used the program E-SURGE for model selection and parameter estimation (Choquet et al. 2009). To limit the number of parameters, we did not test for a time effect on the detection probability, as the major part of detection heterogeneity was accounted by the dispersal states. We constrained the probability of dying from a given cause to depend only on the distance (dist) at which the individual was recovered $(<1000 \mathrm{~m}$ or $>1000$ $\mathrm{m}$ from the site of origin) to avoid separability problems with state-dependent survival probabilities, and we fixed the probability of being shot to zero during the non- 
TABLE 2. Model selection based on the Akaike information Criterion, corrected for lack of fit and small sample size (QAIC $)$ for survival.

\begin{tabular}{|c|c|c|c|c|c|}
\hline Model notation & $k$ & Deviance & $\mathrm{QAIC}_{\mathrm{c}}$ & $\Delta \mathrm{QAIC}_{\mathrm{c}}$ & QAIC $_{c}$ weight \\
\hline \multicolumn{6}{|c|}{ Step 1, biological factors } \\
\hline $\begin{array}{l}S_{\text {state }} \dagger \\
S_{\text {state+age }}+ \\
S_{\text {state×age }}\end{array}$ & $\begin{array}{l}20 \\
21 \\
23\end{array}$ & $\begin{array}{l}1915.05 \\
1914.54 \\
1910.84\end{array}$ & $\begin{array}{l}1597.94 \\
1599.63 \\
1600.83\end{array}$ & $\begin{array}{l}0 \\
1.69 \\
2.90\end{array}$ & $\begin{array}{l}0.49 \\
0.21 \\
0.12\end{array}$ \\
\hline \multicolumn{6}{|l|}{ Step 2, period } \\
\hline $\begin{array}{l}S_{\text {state+age } \times \text { hper }} \dagger \\
S_{\text {state+hper }}^{\dagger} \\
S_{\text {state+hper+age }}\end{array}$ & $\begin{array}{l}23 \\
21 \\
22\end{array}$ & $\begin{array}{l}1902.23 \\
1908.11 \\
1907.74\end{array}$ & $\begin{array}{l}1593.83 \\
1594.40 \\
1596.20\end{array}$ & $\begin{array}{l}0 \\
0.57 \\
2.37\end{array}$ & $\begin{array}{l}0.40 \\
0.30 \\
0.12\end{array}$ \\
\hline
\end{tabular}

Notes: Only models up to the first that differs by more than two $\mathrm{QAIC}_{\mathrm{c}}$ points $\left(\Delta \mathrm{QAIC} \mathrm{C}_{\mathrm{c}}>2\right)$, are presented in each step. All models are detailed in Appendix D: Table D1. Step 1 shows the effect of the biological factors state, age, and sex on survival probability starting from the model $S_{\text {statexsex } \times a g e}$ where survival varied by state (stationary, transient, disperser), sex, and age in a multiplicative way. Step 2 shows the effect of the period (hper; non-hare-hunting vs. hare-hunting period) once the main factors among age, sex, and state have been selected in step 1. In both steps, the model structure for dispersal parameters, mortality causes, collar battery, and detection probability remains the same. The variable $k$ represents the number of parameters in the model.

$\dagger$ The selected model.

\$ Models receiving equal support from the data.

hunting period for hares (running the model without fixing the recovery led to similar results). As a result, we focused only on factors affecting dispersal movements and survival. We considered three endogenous and two exogenous factors that could potentially influence both dispersal and survival probabilities: (1) dispersal state (S, $\mathrm{T}$, or D); (2) age (juveniles and adults, denoted juv and ad when factors are tested separately on each age class); (3) sex; (4) period (noted hper), modeled as a two-level factor: hare-hunting ( $\mathrm{hH}$, autumn) or non-hare-hunting period $(\mathrm{NhH}$, rest of the year); alternatively, (5) season (noted seas), modeled as a three-level factor including the non-hunting and harvesting periods $(\mathrm{NH})$, the harehunting $(\mathrm{hH})$ period, and the roe deer drive hunt $(\mathrm{rdH})$ season (winter), which includes the beginning of the hare breeding season.

We started with the general model $\left(\varepsilon_{\text {seas }} \delta_{\text {sex } \times j u v+a d}\right.$ $\sigma_{\text {seas }}$ ), where the foray probability $\varepsilon$ and the permanent dispersal probability $\sigma$ depend on the season as suggested by the GOF, and the probability $\delta$ that a dispersing individual settles depends on the age and sex of juveniles, as previously shown (Bray et al. 2007, Avril et al. 2011). For survival probabilities, we started with the general model $\left(S_{\text {state } \times \text { agexsex }}\right)$, where survival was state dependent and varied with sex and age in a multiplicative way. We then selected the main factors explaining variations in parameters in a three-step approach: (1) we first chose the best model among those that assumed state, age, or sex might influence survival parameters; (2) we examined variants of the best model from step 1 that incorporated the effects of the season or period, as defined above, on survival. We then tested the effect of distance (dist) from the site of origin on mortality causes. (3) Starting from the previously defined best model structure for survival and mortality causes in step 2, we specifically tested for the main factors explaining variations in dispersal probabilities, following a two-step approach: starting from the general model $\varepsilon_{\text {seas }} \delta_{\text {sex } \times j u v+a d} \sigma_{\text {seas }}$, we selected the best model structure for each focal parameter, $\varepsilon, \delta$, or $\sigma$, keeping the structure of that starting model for the other dispersal parameters. Then, once the main source of variation in each focal parameter had been detected, we built a set of composite models, combining the best model structures for each focal parameter and compared them to the whole set of models tested.

We used the Akaike information criterion, corrected for lack of fit and small sample size $\left(\mathrm{QAIC}_{\mathrm{c}}\right.$; Burnham and Anderson 2002), to perform model selection. At each step, we also computed $\mathrm{QAIC}_{\mathrm{c}}$ weights (the normalized $\mathrm{QAIC}_{\mathrm{c}}$ values), which gave us the probability that the focal model was the best one compared to the other models at that step. Because convergence on local minima is a typical concern in MS-CR analysis, we reran each model at least 15 times using different random initial values. We also relied on E-SURGE to check for parameter identifiability (Gimenez et al. 2003) and boundary parameters.

\section{Results}

\section{Survival and mortality causes}

Before investigating the influence of factors on variation in hare survival, we first tested whether accounting for the distance (dist) on the detection probability affected the fit of the general starting model. In the following selection procedure, the detection probability was shown to always vary with dist, as the model with constant detection probability did not fit the data better $\left(\mathrm{QAIC}_{\mathrm{c}}=1628.80\right.$ vs. 1611.11$)$. As expected, the detection probability was higher for individuals at $<1000 \mathrm{~m}$ from their site of origin, approaching one $\left(\hat{p}_{1}=\right.$ $0.97 \pm 0.01, \hat{p}_{2}=0.85 \pm 0.03$; mean estimates $\pm \mathrm{SE}$ given by the best selected model in step 3).

Among the models used to assess the effects of state, age, and sex on survival (Table 2, step 1), the models $S_{\text {state, }}$ in which survival was state dependent $\left(\mathrm{QAIC}_{\mathrm{c}}=\right.$ 
1597.94) and the model $S_{\text {state+age, }}$ in which survival varied with state and age $\left(\mathrm{QAIC}_{\mathrm{c}}=1599.63\right)$ in an additive way were retained as the most plausible ones. We therefore investigated the influence of the period (hper) on survival, starting with the models $S_{\text {state }}$ and $S_{\text {state+age. }}$

The models $S_{\text {hper+state, }}$ in which survival varied with state and hper in an additive way $\left(\mathrm{QAIC}_{\mathrm{c}}=1594.40\right)$, and $S_{\text {hper } \times a g e+s t a t e}$, in which survival depended on the interaction hper and age, plus an additive effect of the state $\left(\mathrm{QAIC}_{\mathrm{c}}=1593.83\right)$, were retained as the most plausible ones. These models showed higher support from the data than the previous model, $S_{\text {state }}\left(\Delta \mathrm{QAIC}_{\mathrm{c}}\right.$ $>3.54$ ), and they fit the data as well. Overall, survival was higher during the $\mathrm{NhH}$ period, whatever the state (Fig. 2a, estimates given by the best model in step 3). Stationary hares showed higher survival than hares in any other state $\left(\hat{S}^{\mathrm{S}}=0.94 \pm 0.01,0.89 \pm 0.02\right.$ during the $\mathrm{NhH}$ and the hH periods, respectively). Hares experienced the lowest survival during transience and early settlement stages, i.e., during the month following departure $\left(\hat{S}^{\mathrm{T}}=0.68 \pm 0.07,0.54 \pm 0.06\right.$ during the $\mathrm{NhH}$ and $\mathrm{hH}$ periods, respectively). In addition, the model $S_{\text {hper×age+state }}$ revealed that juveniles in the dispersal state experienced lower survival during the $\mathrm{hH}$ period than adults $\left(\hat{S}^{\mathrm{D}}=0.79 \pm 0.04,0.86 \pm 0.04\right.$, respectively).

Keeping the model structure $S_{\text {hper+state }}$ or $S_{\text {hper } \times a g e+s t a t e}$ for survival probabilities and removing the effect of dist on the proportion of individuals dying from different causes did not improve the model's fit $\left(\mathrm{QAIC}_{\mathrm{c}}=1596.51, \mathrm{QAIC}_{\mathrm{c}}=1596.33\right.$, for models $S_{\text {hper+state; }} ; \alpha_{\text {hper }}$ or $S_{\text {hper } \times a g e+s t a t e} ; \alpha_{\text {hper, }}$, respectively). Estimates of both models showed that the proportion of individuals shot was higher at $>1000 \mathrm{~m}\left(\hat{\alpha}^{\mathrm{S}}=0.33 \pm\right.$ $0.18 ; \hat{\alpha}^{\mathrm{TD}}=0.79 \pm 0.07$, respectively; Fig. $2 \mathrm{~b}$ ).

\section{The dispersal step}

We selected the best model structure for dispersal parameters, keeping the model structure for survival and mortality parameters, $S_{\text {hper+state; }} \alpha_{\text {hper } \times \text { dist }}$, constant. Following the principle of parsimony (Lebreton et al. $1992)$, we chose the model $S_{\text {hper+state; }} ; \alpha_{\text {hper } \times \text { dist }}$ rather than $S_{\text {hper } \times \text { age+state }} ; \alpha_{\text {hper } \times \text { dist }}$ for survival and mortality parameters. Starting from the other model did not change the model ranking (results not shown).

In the foray step, the model $\varepsilon_{\text {seas }} \delta_{\text {juv } \times \text { sex+age }} \sigma_{\text {seas }}$, in which the foray rate $\varepsilon$ depends on seas, showed high support from the data compared to the other models $\left(\triangle \mathrm{QAIC}_{\mathrm{c}}=7.50\right)$ and was retained as the best model explaining variation in $\varepsilon$ (Table 3 ). For the settlement probability $\delta$, we retained three plausible models differing by less than $2 \mathrm{QAIC}_{\mathrm{c}}$ points from the best one, in which $\delta$ was constant (model $\varepsilon_{\text {seas }} \delta_{(\text {.) }} \sigma_{\text {seas }}$ ). We did not consider the effect of the season on $\delta$ because it led to non-estimable parameters, mainly because there were insufficent data in the $\mathrm{NH}$ period. Instead, we tested for the two-level factor period hper. In the third
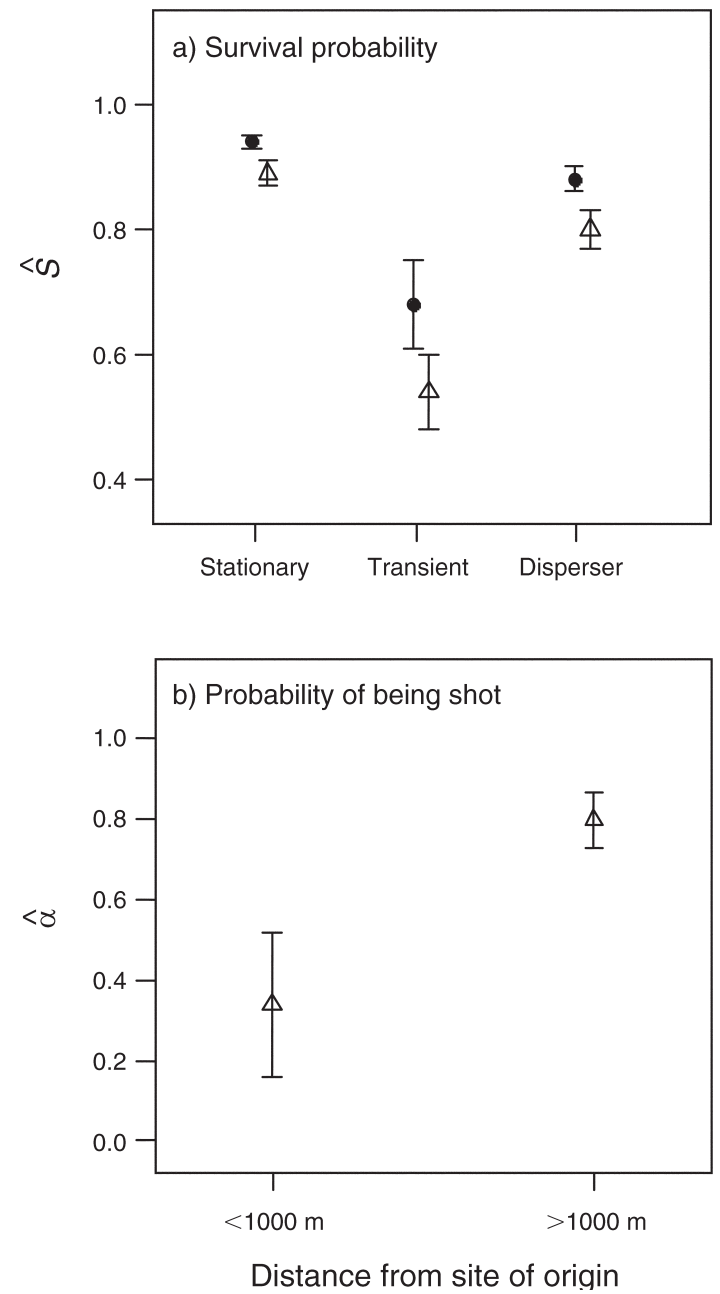

FIG. 2. (a) Monthly state-dependent survival rates, $\hat{S}$ (mean $\pm \mathrm{SE}$ ) according to the period of the year (hper; black circles, non-hare-hunting period; black triangles, hare-hunting period). (b) Proportions, $\hat{\alpha}$ (mean $\pm \mathrm{SE}$ ) of individuals shot according to the distance $(\mathrm{m})$ from the site of origin at which a hare was recovered. Estimates were derived from model $S_{\text {state+hper }}$ for survival and $\alpha_{\mathrm{hper} \times \text { dist }}$ for mortality causes.

step, which describes the permanent dispersal probability $\sigma$, adding sex or age effects did not increase the model fit compared to the model in which $\sigma$ was constant.

Given those results, we built a set of composite models, combining the best-selected model structure for each focal parameter, and tested which one was best supported by the data. The best composite model was the one in which $\varepsilon$ depends on seas and both $\delta$ and $\sigma$ depend on age (model $\varepsilon_{\text {seas }} \delta_{\text {age }} \sigma_{\text {age }}$ ). This composite model fit the data as well as the five other models $\left(\Delta\right.$ QAIC $\left._{c}<2\right)$, showing lower $\mathrm{QAIC}_{\mathrm{c}}$ than any other model tested. In four of these six plausible models, the age class explained much of the variation in $\delta$, whereas $\sigma$ was constant in three of them $(\hat{\sigma}=0.97 \pm 0.01)$. We therefore retained the model $\varepsilon_{\text {seas }} \delta_{\text {age }} \sigma_{(.)}$to describe the 
TABLE 3. Model selection based on QAIC $_{\mathrm{c}}$ for dispersal parameters in step 3.

\begin{tabular}{|c|c|c|c|c|c|}
\hline Model notation/focal parameter & $k$ & Deviance & $\mathrm{QAIC}_{\mathrm{c}}$ & $\Delta \mathrm{QAIC}_{\mathrm{c}}$ & QAIC $_{\mathrm{c}}$ weight \\
\hline \multicolumn{6}{|l|}{ 1) Foray probability } \\
\hline $\begin{array}{l}\varepsilon_{\text {seas }} \delta_{\text {juv } \times \text { sex }+ \text { ad }} \sigma_{\text {seas }} \dagger \\
\varepsilon_{\text {juv } \times \text { sex }+ \text { ad }} \delta_{\text {juv } \times \text { sex }+ \text { ad }}\end{array}$ & $\begin{array}{l}21 \\
21\end{array}$ & $\begin{array}{l}1908.11 \\
1917.33\end{array}$ & $\begin{array}{l}1594.40 \\
1601.90\end{array}$ & $\begin{array}{l}0 \\
7.50\end{array}$ & $\begin{array}{l}0.97 \\
0.02\end{array}$ \\
\hline \multicolumn{6}{|l|}{ 2) Settlement probability } \\
\hline $\begin{array}{l}\varepsilon_{\text {seas }} \delta_{\text {age }} \sigma_{\text {seas }} \dagger \\
\varepsilon_{\text {seas }} \delta_{(.)} \sigma_{\text {seas }} \dagger \\
\varepsilon_{\text {seas }} \delta_{\text {hper+age }} \sigma_{\text {seas }} \hbar \\
\varepsilon_{\text {seas }} \delta_{\text {hper } \times \text { age }} \sigma_{\text {seas }}\end{array}$ & $\begin{array}{l}20 \\
19 \\
21 \\
22\end{array}$ & $\begin{array}{l}1907.79 \\
1911.68 \\
1907.16 \\
1905.13\end{array}$ & $\begin{array}{l}1592.04 \\
1593.10 \\
1593.63 \\
1594.08\end{array}$ & $\begin{array}{l}0 \\
1.07 \\
1.59 \\
2.04\end{array}$ & $\begin{array}{l}0.32 \\
0.19 \\
0.14 \\
0.12\end{array}$ \\
\hline \multicolumn{6}{|l|}{ 3) Permanent dispersal probability } \\
\hline $\begin{array}{lll}\varepsilon_{\text {seas }} & \delta_{\text {juv } \times \text { sex }+ \text { ad }} & \sigma_{\text {age }} \dagger \\
\varepsilon_{\text {seas }} & \delta_{\text {juv } \times \text { sex }+ \text { ad }} & \sigma_{(.)}^{\dagger} \\
\varepsilon_{\text {seas }} & \delta_{\text {juv } \times \text { sex }+a d} & \sigma_{\text {sex }} \\
\varepsilon_{\text {seas }} & \delta_{\text {juv } \times \text { sex }+ \text { ad }} & \sigma_{\text {seas }}\end{array}$ & $\begin{array}{l}20 \\
19 \\
20 \\
21\end{array}$ & $\begin{array}{l}1904.77 \\
1907.91 \\
1906.88 \\
1908.11\end{array}$ & $\begin{array}{l}1589.58 \\
1590.04 \\
1591.29 \\
1594.40\end{array}$ & $\begin{array}{l}0 \\
0.46 \\
1.71 \\
4.82\end{array}$ & $\begin{array}{l}0.43 \\
0.34 \\
0.18 \\
0.04\end{array}$ \\
\hline \multicolumn{6}{|l|}{ 4) Composite models } \\
\hline $\begin{array}{l}\varepsilon_{\text {seas }} \delta_{\text {age }} \sigma_{\text {age }} \ddagger \\
\varepsilon_{\text {seas }} \delta_{\text {age }} \sigma_{(.)}^{\dagger} \\
\varepsilon_{\text {seas }} \delta_{(.)} \sigma_{(.) \dagger} \\
\varepsilon_{\text {seas }} \delta_{\text {age }} \sigma_{\text {sex }} \neq \\
\varepsilon_{\text {seas }} \delta_{(.)} \sigma_{\text {age }} \neq \\
\varepsilon_{\text {seas }} \delta_{\text {hper+age }} \sigma_{(.)} \ddagger\end{array}$ & $\begin{array}{l}19 \\
18 \\
17 \\
19 \\
18 \\
19\end{array}$ & $\begin{array}{l}1904.84 \\
1907.92 \\
1911.90 \\
1906.93 \\
1909.83 \\
1907.26\end{array}$ & $\begin{array}{l}1587.54 \\
1587.96 \\
1589.11 \\
1589.24 \\
1589.51 \\
1589.51\end{array}$ & $\begin{array}{l}0 \\
0.42 \\
1.56 \\
1.70 \\
1.97 \\
1.97\end{array}$ & $\begin{array}{l}0.26 \\
0.21 \\
0.12 \\
0.11 \\
0.10 \\
0.10\end{array}$ \\
\hline
\end{tabular}

Notes: Only models up to the first that differs by more than two $\mathrm{QAIC}_{\mathrm{c}}$ points $\left(\Delta \mathrm{QAIC} \mathrm{c}_{\mathrm{c}}>2\right)$ are presented in each step. All models are detailed in Appendix D: Table D2. The models for foray, settlement, and dispersal probabilities (groups 1, 2, and 3) show the effect of the season, seas (nonhunting, hare-hunting, roe deer hunts) or the period, hper (hunting of hares or no), age (juvenile, juv; adults, ad), and sex for each focal parameter: the foray probability, $\varepsilon$; the settlement probability, $\delta$; and the permanent dispersal probability, $\sigma$, respectively; starting from the model $\varepsilon_{\text {seas }} \delta_{\text {juv } \times \text { sex }+ \text { ad }} \sigma_{\text {seas }}$ where $\varepsilon$ and $\sigma$ depend on seas and $\delta$ depends on age and sex in juveniles only. Group 4 shows the composite models that include the main source of variation for each focal parameter. In both steps, the model structure for survival, mortality causes, collar battery, and detection parameters remains the same.

$\uparrow$ The selected model.

$\$$ Models receiving equal support from the data.

main variations in the data, as it differed by $0.42 \mathrm{QAIC}_{\mathrm{c}}$ points from the best one; furthermore, estimates of $\sigma$ given by the model $\varepsilon_{\text {seas }} \delta_{\text {age }} \sigma_{\text {age }}$ were high and similar, whatever the age class $(\hat{\sigma}=0.94 \pm 0.06 ; 0.98 \pm 0.02$, in juveniles and adults, respectively).

Estimates from the model $\varepsilon_{\text {seas }} \delta_{\text {age }} \sigma_{(.)}$showed that the foray rate $\varepsilon$ was high during the $\mathrm{hH}$ period $(\hat{\varepsilon}=0.28$ \pm 0.04 ), whereas it decreased significantly during the rest of the year $(\mathrm{NH}, \hat{\varepsilon}=0.11 \pm 0.02$; roe deer hunt, $\mathrm{rdH}, \hat{\varepsilon}=0.09 \pm 0.03$; Fig. 3a). This model also showed that the settlement probability was higher in juveniles than in adults $(\hat{\delta}=0.75 \pm 0.08 ; 0.44 \pm 0.13$, respectively), regardless of sex or seas (Fig. 3b). In addition, as suggested by the GOF tests, dispersing individuals were not always relocated immediately, and some of them disappeared definitely (they may have been alive and long-distance dispersers or may have died from causes other than hunting); among dispersing individuals, $25 \%$ on average disappeared temporarily $(\hat{\zeta}=0.25 \pm 0.10)$, while only $15 \%$ were found again later on in the dispersal state $(\hat{\tau}=0.15 \pm 0.10)$. Note that this difficulty concerned few individuals in the data set; among the 152 individuals, 19 disappeared and were never relocated; no hare disappeared during the $\mathrm{hH}$ period and only 4 disappeared in the two months before the $\mathrm{hH}$ period, suggesting that disappearances were probably not related to unreported hunting.

\section{Discussion}

\section{Transience and hunting make dispersal costly}

We benefited from a large sample size of radiocollared hares and modeling dispersal as a three-stage hierarchical process. We found that hares in our population incurred higher mortality rates in the month following departure from their site of origin (i.e., during forays and early settlement period into a new site) than hares that remained stationary or had dispersed and settled more than two months previously in a new site. In addition, we found that hunting plays a significant role in dispersers' mortality, both during transience and after settlement. In agreement with our expectations, this result clearly demonstrates that the risks related to transience through and settlement into unfamiliar habitats may be responsible for most of the survival differences between philopatric individuals and dispersers.

This conclusion contrasts with those of Devillard and Bray (2009), who suggested that the transient stage was not responsible for the main dispersal survival cost in this species. These authors did not account for "shifter" dispersers that exhibit a long-duration transient stage in their study, and they did not consider individuals that left their natal area and died soon after (i.e., died during exploratory forays before returning to or permanently 
leaving their site of origin) because their MS-CR model did not support uncertainty concerning the dispersal state of individuals (Bray et al. 2007). Their approach might thus underestimate mortality during the transient stage. In our work, among individuals dying in the month following departure from the site of origin, some may have actually died soon after they had successfully moved and settled for several days in their new site. Although our "transient" stage also includes the early settlement period (so that it cannot give the survival cost of the movement per se), our data give information about the influence of transience and unfamiliarity with settlement habitats on disperser survival. Omitting this stage reveals that survival rates of stationary and dispersing hares that had settled a long time previously were, in contrast, quite similar. This pattern illustrates why studies that did not account for the transient stage failed to detect survival differences between residents and emigrants (e.g., in red squirrels, Sciurus vulgaris; Wauters et al. 1994) and why other studies always found low survival rates for dispersers compared to philopatric individuals when the state disperser included both transience and the later settlement period (e.g., in the kangaroo rats, Dipodomys spectabilis; Waser 1988).

We also found survival to be lower during the harehunting $(\mathrm{hH})$ period compared to the non-hunting $(\mathrm{NH})$ period. Because of parameter identifiability constraints, we could not precisely assert whether individuals were preferentially shot during transience or after having settled in their new habitat; however, an estimation of the probability of being shot in state $\mathrm{T}$ (transient) and D (settled disperser) by the products $\left(1-S^{\mathrm{T}}\right) \alpha^{\mathrm{TD}}$ and $(1-$ $\left.S^{\mathrm{D}}\right) \alpha^{\mathrm{TD}}$, respectively, suggests that hares should have twice as high a risk of death from being shot during transience and early settlement periods as they would have later ( 0.36 vs. 0.17$)$. This effect may be explained in two nonexclusive ways. First, the risk of being shot during transience may increase because transient individuals are easy targets. When approached, hares crouch in their forms to evade detection before flushing. This behavior is even more pronounced in open landscapes where coursing occurs (Hutchings and Harris 1995). In our population, the $\mathrm{hH}$ period followed the harvest. Dispersing hares searching for new ranges through low vegetation cover, with poor knowledge of form locations or of where to find refuges, are undoubtedly more vulnerable to foxes or hunters and their dogs than are less active resident individuals. Second, a higher risk of being shot during transience might result from a higher foray rate during the $\mathrm{hH}$ period. Among transients, juveniles were more prone to settle in a new site, in agreement with the observed higher dispersal rates in juvenile hares; however, a higher foray rate during this time contrasts with work showing that natal dispersal movements were not affected by hunting (Bray et al. 2007, Avril et al. 2011). Because those works focused only on hares settled for long enough to be confidently considered dispersers, they probably missed the hares
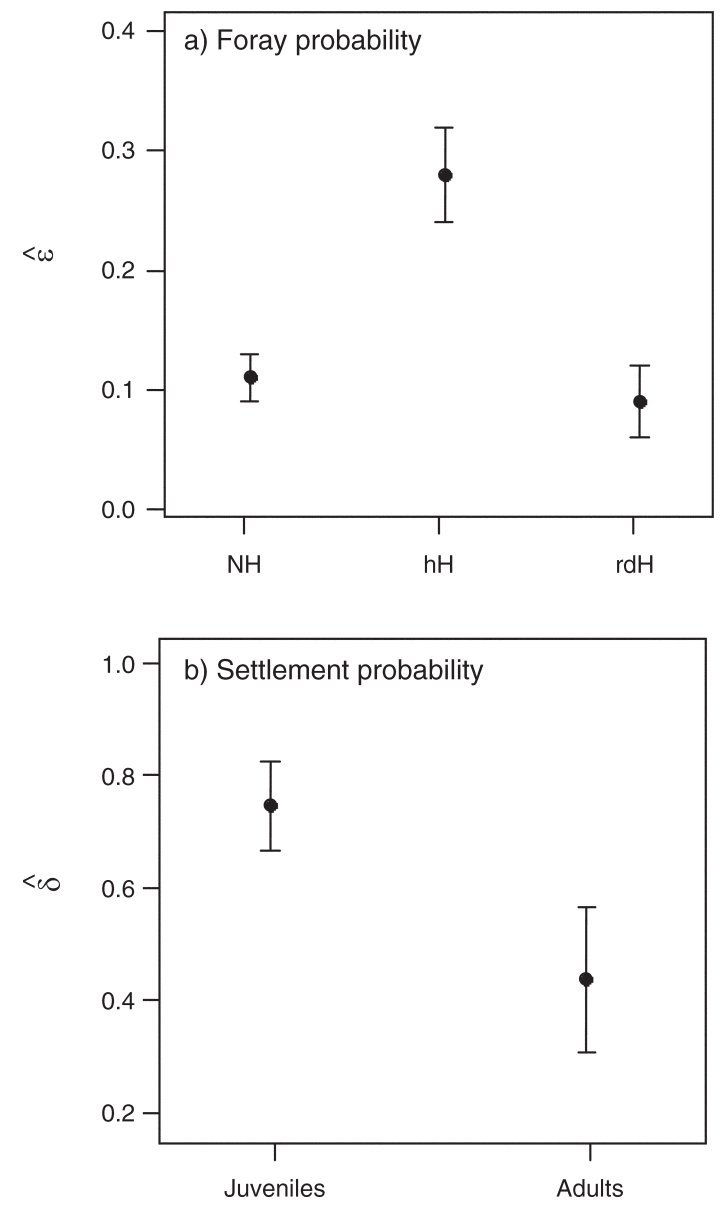

FIG. 3. (a) Monthly foray probability, $\hat{\varepsilon}$ (mean \pm SE) according to the season (seas; $\mathrm{NH}$, non-hunting period; $\mathrm{hH}$, hare-hunting; rdH, roe deer drive hunt). (b) Monthly settlement probability, $\hat{\delta}$ (mean $\pm \mathrm{SE}$ ) according to the age of hares. Estimates were derived from model $\varepsilon_{\text {seas }} \delta_{\text {age }} \sigma_{(.)}$.

that were killed soon after leaving their sites of origin during the $\mathrm{hH}$ period. In our data, departures during the $\mathrm{hH}$ period occurred preferentially during the first month (12 out of 27), when many hares were shot (15 out of 49), suggesting that many more transient hares could be killed soon after leaving their site of origin than was previously believed to be the case.

Finally, one may also wonder whether hunting-related disturbances are responsible for higher foray rates during the $\mathrm{hH}$ period, especially for individuals $>180$ days old, which were known to be highly sedentary in our population (Avril et al. 2011). Hunting-related disturbances could affect an individual dispersal decision, either during departure or during settlement, much like predation (Weisser 2001). For example, hunting has been shown to induce breeding dispersal in Tengmalm's Owl, Aegolius funereus (Hakkarainen et al. 2001). In our data, one female monitored during two consecutive hH periods dispersed during the first one and returned in the next one, suggesting that hunting could also have some 


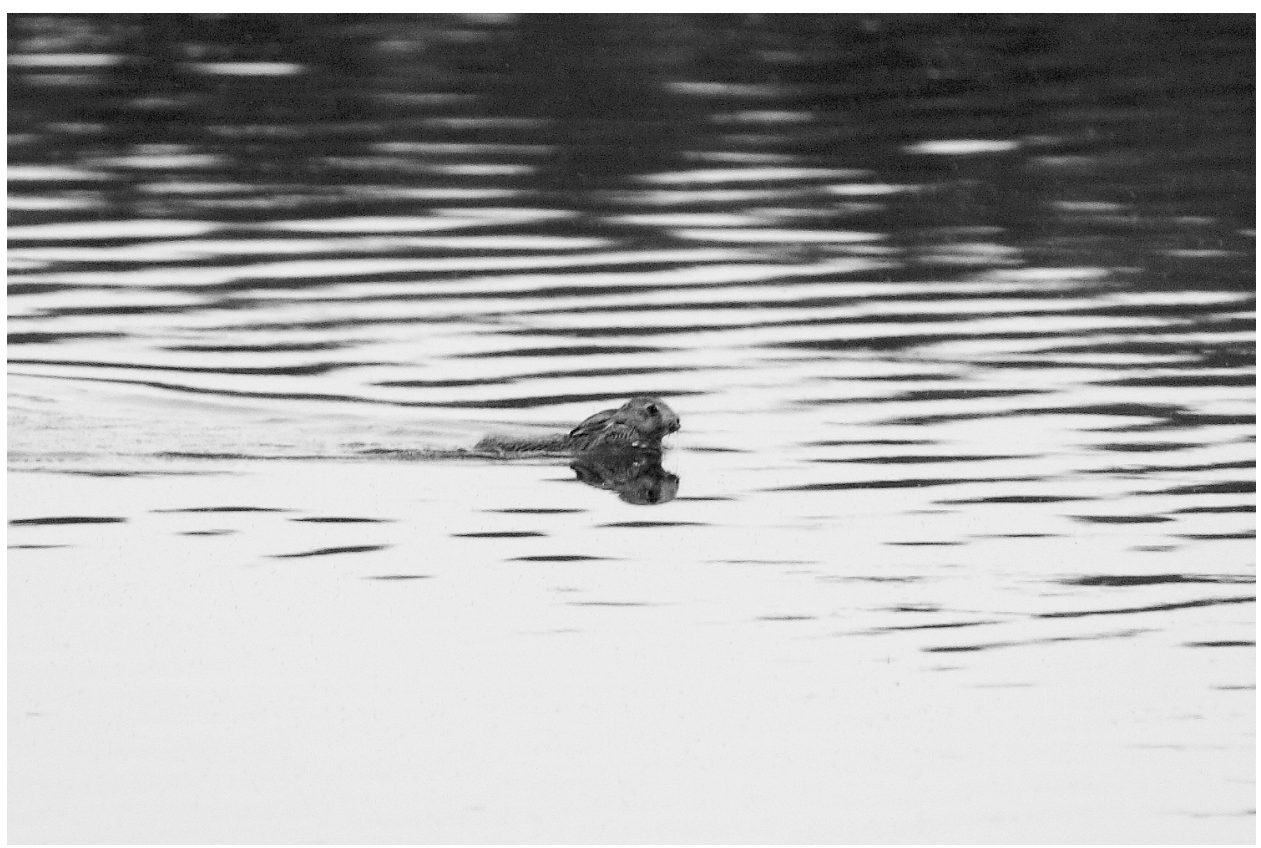

Plate 1. A European hare crossing the Loire River near the study site in central France. Photo credit: Sylvain Richier.

impact on dispersal of hares. High foray rates during the $\mathrm{hH}$ period may be triggered by drive hunts, but they may also reflect failed settlement into a new site, owing to increasing hunting-related disturbances.

\section{MS-CR models to investigate stage-dependent dispersal}

Most studies fail to evaluate the survival cost during the transience stage, mainly because of the difficulties in knowing whether lost individuals were emigrant, dead, and non-recovered philopatrics or dispersers that had died unrecovered during emigration (Daly et al. 1990). GOF tests on our data show that stationary individuals disappearing at one occasion tended to be detected again later in the dispersal state, illustrating the difficulty. The MS-CR model that we developed here may help us to manage with two main problems. First, modeling dispersal as a three-stage process allowed us to obtain reliable estimates of stage-dependent survival rates and dispersal probabilities, as well as estimates of the "realized dispersal/emigration propensity ratio." We emphasize that this modeling approach could be used in other species to obtain such estimates, simply by adjusting the length of the capture occasion to the average length of the species-specific transient stage. Second, using "temporarily undetectable" dispersal states, our model formulation also accounted for uncertainty about whether emigrants had temporarily or definitely disappeared (e.g., whether they were living or dead). We could add such "temporarily undetectable" states because we expected the detection probability to be sufficiently high, given the use of telemetry data, to ensure that an individual not detected in the study site was alive or dead in the disperser state. Accordingly, the detection probability approached one, and it was higher when the individual was $<1000 \mathrm{~m}$ from its site of origin, confirming that individuals in the disperser state far from their trapping location were more difficult to detect simply owing to a low sampling effort off the study site. The use of telemetry data, however, required modeling additional detectability parameters compared to classical capture-recapture models because the detection of individuals also depends on the collar battery life. We modeled detectability as a logit function decreasing with the individual radio tracking duration. More appropriate functions, such as the Gompertz function, could be used, but the logit link was preferred because of software compatibility. The omission of that parameter did not drastically change the parameters of interest, possibly because of the high rate of detection; however, we found that removing this information changed the apparent effect of age on the settlement probability, which was the only parameter in our model varying with the age class. Potential biases in detection probability from the end of the battery life should concern mainly "old" individuals, as most fitted hares were juveniles at the time of capture in our research. We emphasize that the selected model did not allow us to detect significant changes in parameter estimates between models that accounted for the life expectancy of the radio battery and those that did not because few parameters were age related. Nevertheless, we advocate modeling this variable to improve the reliability of the parameter estimates and perhaps of the biological inferences in the context of 
sparse data. However, tests are needed to verify that modeling this parameter does not affect model selection.

\section{Conclusions and management perspectives}

Four main points emerge from our results. First, we demonstrated that survival rates between philopatric individuals and dispersers that are established in their new site may be similar, provided that the qualities of the old and new habitats do not strongly differ. This result was expected in our study area (Avril et al. 2011), but in a more heterogeneous environment, the costs related to the transient stage should only be offset if the dispersers settle in a more suitable habitat. Second, the propensity for dispersal during the hunting period in this species is higher than previously thought, probably because previous works missed transient individuals that were killed during this time. As previously suggested (Devillard and Bray 2009), the hunting period should be delayed to ensure that most dispersers have successfully settled and perhaps reproduced in their new sites. In addition, it is important to determine whether the observed high foray rates are partially linked to hunting-related disturbances. Third, high mortality from hunting and movement through unfamiliar habitats during transience suggests that selection should favor dispersal events earlier in the season and shorter-distance dispersers. This may be actually the case, as shifter dispersal movements (shortdistance dispersal) occurred later in the season and were more common during the hunting period ( 7 out of 10 ) than long-distance "one-way" dispersers. Finally, in the more general context of dispersal studies, the high mortality risks of transience underline that emigration rates alone are not sufficient to give information about the colonization potential of a given species. Using estimates given by our model during the non-hunting period, among the $11 \%$ of juveniles that forayed in a month and that were potential emigrants, 32\% died during transience, and among the survivors (68\%), only $75 \%$ settled successfully, leading in turn to a realized monthly dispersal rate of half the emigration propensity. This last result strongly emphasizes the need to account for the entire dispersal process to gain insights into population dynamics and dispersal evolution.

\section{ACKNOWLEDGMENTS}

This study was supported by the ONCFS and the Fédération Départementale des Chasseurs du Loir-et-Cher (FDC41). We thank J. D. Lebreton and S. Devillard for their suggestions about the elaboration of the ideas presented in the manuscript, L. Crespin, A. Viallefont, and R. Choquet for their help in the analysis and software use. We also thank two anonymous referees for constructive comments. Finally, we thank the agents of the ONCFS and the FDC41 for the data collection, the farmers, J. P. Blot and J. L. Fesneau, and the hunters of La Chapelle-Maves and their respective presidents J. C. Dodin and M. Huard.

\section{Literature Cited}

Avril, A., Y. Léonard, J. Letty, R. Péroux, J. S. Guitton, and D. Pontier. 2011. Natal dispersal of European hare in a high density population. Mammalian Biology 76:148-156.
Bélichon, S., J. Clobert, and M. Massot. 1996. Are there differences in fitness components between philopatric and dispersing individuals. Acta Oecologica International Journal of Ecology 17:503-517.

Bowler, D. E., and T. G. Benton. 2009. Variation in dispersal mortality and dispersal propensity among individuals: the effects of age, sex and resource availability. Journal of Animal Ecology 78:1234-1241.

Bray, Y., S. Champely, and D. Soyez. 2002. Age determination in leverets of European hare Lepus europaeus based on body measurements. Wildlife Biology 8:31-39.

Bray, Y., S. Devillard, E. Marboutin, B. Mauvy, and R. Peroux. 2007. Natal dispersal of European hare in France. Journal of Zoology 273:426-434.

Burnham, K. P., and D. R. Anderson. 2002. Model selection and inference: a practical information-theoretic approach. Springer-Verlag, New York, New York, USA.

Choquet, R., L. Rouan, R. Pradel, D. L. Thomson, E. G. Cooch, and M. J. Conroy. 2009. Program E-Surge: a software application for fitting multievent models. Modeling demographic processes in marked populations. Pages 845865 in G. P. Patil, editor. Environmental and ecological statistics. Springer, New York, New York, USA.

Clobert, J., E. Danchin, A. A. Dhondt, and J. D. Nichols. 2001. Dispersal. Oxford University Press, New York, New York, USA.

Daly, M., M. Wilson, P. R. Behrends, and L. F. Jacobs. 1990. Characteristics of kangaroo rats, Dipodomys merriami, associated with differential predation risk. Animal Behaviour 40:380-389.

Devillard, S., and Y. Bray. 2009. Assessing the effect on survival of natal dispersal using multistate capture-recapture models. Ecology 90:2902-2912.

Dobson, F. S. 1982. Competition for mates and predominant juvenile male dispersal in mammals. Animal Behaviour 30:1183-1192.

Gadgil, M. 1971. Dispersal: population consequences and evolution. Ecology 52:253-261.

Gaines, M. S., and L. R. McClenaghan. 1980. Dispersal in small mammals. Annual Review of Ecology and Systematics 11:163-196.

Gimenez, O., R. Choquet, and J. D. Lebreton. 2003. Parameter redundancy in multistate capture-recapture models. Biometrical Journal 45:704-722.

Greenwood, P. J. 1980. Mating systems, philopatry and dispersal in birds and mammals. Animal Behaviour 28:1140-1162.

Hakkarainen, H., P. Ilmonen, V. Koivunen, and E. Korpimäki. 2001. Experimental increase of predation risk induces breeding dispersal of Tengmalm's owl. Oecologia 126:355359.

Hamilton, W. D., and R. M. May. 1977. Dispersal in stable habitat. Nature 269:578-581.

Hanski, I. 1999. Metapopulation ecology. Oxford University Press, Oxford, UK.

Holley, A. J. F. 1993. Do Brown hares signal to foxes. Ethology 94:21-30.

Hutchings, M. R., and S. Harris. 1995. Does hunting pressure affect the flushing behaviour of brown hares (Lepus europaeus)? Journal of Zoology 237:663-667.

Ims, R. A., and D. Ø. Hjermann. 2001. Condition-dependent dispersal. Pages 209-222 in J. Clobert, E. Danchin, A. A. Dhondt, and J. D. Nichols, editors. Dispersal. Oxford University Press, Oxford, UK.

Johnson, C. A., J. M. Fryxell, I. D. Thompson, and J. A. Baker. 2009. Mortality risk increases with natal dispersal distance in American martens. Proceedings of the Royal Society B 276:3361-3367.

Larsen, K., and S. Boutin. 1994. Movements, survival, and settlement of red squirrel (Tamiasciurus hudsonicus) offspring. Ecology 75:214-223. 
Lebreton, J. D., T. Almeras, and R. Pradel. 1999. Competing events, mixtures of information and multistratum recapture models. Bird Study 46:39-46.

Lebreton, J. D., K. P. Burnham, J. Clobert, and D. R. Anderson. 1992. Modeling survival and testing biological hypotheses using marked animals: a unified approach with case studies. Ecological Monographs 62:67-118.

Lebreton, J. D., and R. Pradel. 2002. Multistate recapture models: modelling incomplete individual histories. Journal of Applied Statistics 29:353-369.

Lidicker, W. Z. 1975. The role of dispersal in the demography of small mammals. Pages 103-128 in F. B. Golley, K. Petrusewicz, and L. Ryszkowski, editors. Small mammals: their production and population dynamics. Cambridge University Press, London, UK.

Nichols, J. D., and J. E. Hines. 1993. Survival estimation in the presence of tag loss using joint analysis of capture-recapture data. Pages 229-243 in J. D. Lebreton and P. M. North, editors. Marked individuals in the study of bird populations. Advances in life sciences. Birkhaüser Verlag, Basel, Switzerland.

O'Donoghue, M., and C. Bergman. 1992. Early movements and dispersal of juvenile snowshoe hares. Canadian Journal of Zoology 70:1787-1791.

Pollock, K. H., C. M. Bunck, S. R. Winterstein, and C. L. Chen. 1995. A capture-recapture survival analysis model for radio-tagged animals. Journal of Applied Statistics 22:661672.

Pradel, R. 2005. Multievent: an extension of multistate capturerecapture models to uncertain states. Biometrics 61:442-447.

Pradel, R., O. Gimenez, and J. D. Lebreton. 2005. Principles and interest of GOF tests for multistate capture-recpature models. Animal Biodiversity and Conservation 28:189-204.

Pradel, R., C. M. A. Wintrebert, and O. Gimenez. 2003. A proposal for a goodness-of-fit test to the Arnason-Schwarz multisite capture-recapture model. Biometrics 59:43-53.

Waser, P. M. 1988. Resources, philopatry, and social interactions among mammals. Pages 109-130 in C. N. Slobochikoff, editor. Ecology of the social behavior. Academic Press, New York, New York, USA.

Wauters, L., E. Matthysen, and A. A. Dhondt. 1994. Survival and lifetime reproductive success in dispersing and resident red squirrels. Behavioral Ecology and Sociobiology 34:197201.

Weisser, W. W. 2001. The effect of predation on dispersal. Pages 185-192 in J. Clobert, E. Danchin, A. A. Dhondt, and J. D. Nichols, editors. Dispersal. Oxford Press University, Oxford, UK

Yoder, J. M., E. A. Marschall, and D. A. Swanson. 2004. The cost of dispersal: predation as a function of movement and site familiarity in ruffed grouse. Behavioral Ecology 15:469476 .

\section{Supplemental Material}

Appendix A

From telemetry data to multi-state capture-recapture (MS-CR) histories (Ecological Archives E093-115-A1).

\section{Appendix B}

Model structure and fate diagram (Ecological Archives E093-115-A2).

\section{Appendix C}

Goodness-of-fit tests (Ecological Archives E093-115-A3).

\section{Appendix D}

Supplementary results showing the complete model selection and the effect of modeling the radio-collar battery on the parameters of interest (Ecological Archives E093-115-A4). 